\title{
Prevalence of Intestinal Amoebiasis in Infant and Junior School Children in Degema General Hospital and Environs
}

\author{
${ }^{1}$ NYENKE, C.; ${ }^{2}$ CHUKWUJEKWU, D. C.; ${ }^{3}$ STANLEY, H. O.; ${ }^{4}$ AWOIBI, N. K. \\ ${ }^{I}$ School of Medical Laboratory Science, College of Health Science and Technology Port Harcourt. ${ }^{2}$ Department of Mental Health, \\ University of Port Harcourt Teaching Hospital. ${ }^{3}$ Department of Microbiology University of Port Harcourt. ${ }^{4} \mathrm{C} / O$ School of Medical \\ Laboratory Science, College of Health Science and Technology Port Harcourt. E-Mail OkehStanley@yahoo.com. 08035431710
}

\begin{abstract}
The study was aimed at determining the prevalence of intestinal amoebiasis in infant and junior school children in Degema General Hospital and its environs. 405 stool samples were collected from children within the age group of 1-14 years who attended the Degema General Hospital and three communities of Ileleme, Okpor nd Usokun-Degema. The samples were examined for Entamoeba Histolytica cysts and/or trophozoites. The direct wet preparation and Formol Ether concentration techniques were employed. Forty three (11\%) of the samples were found to be positive for the parasite. Children within the age category of 6-10 yrs had the highest rate of infection. Females $(12.3 \%)$ were more infected than males $(8.8 \%)$ proportionately. In conclusion, the prevalence rates of intestinal amoebiasis among these patients were $11 \%$. Improved sanitation, personal hygiene and deliberate policy by government for rural community health concern will indeed prevent faecal contamination of food and water sources.@JASEM
\end{abstract}

Amoebiasis is a condition due to the infection by the protozoan parasite Entamoeba histolytica. The disease is still considered a major public health problem in developing countries of the world. It is recorded that 450 million persons are infected every year, with an incidence of 50 million, and 100,000 death toll. (Ravdin, Petri, 1995). While amoebiasis is a rare occurrence in developed countries of the world, only found in travelers, immigrants, institutionalized persons and homosexuals, the disease is a common occurrence in the less developed and developing countries of the world. These areas include the tropical and sub-tropical countries of South and West Africa, Central and South America, India and Mexico.(Farthing, Cavellos, Cook, 1996). Among the four species of Entamoeba found in the human gastrointestinal tract, which are Entamoeba hartmanni, E. Coli, E. Disper and E. Histolytic, E. Histolytica is regarded as the invasive type due to its intestinal tissue dissolving carnivorous potential, thus of medical importance (Harold, 1975). Intestinal amoebiasis due to the infection of E. histolytica is ranked third on the list of parasitic protozoan infection leading to death behind malaria and Schistosomiasis (Farthing, Cavellos, Cook, 1996). Some of the commonest means of infection include unsanitary habits, the contamination of food and water by human faeces already infected with the parasite as well as direct faecel-oral contact.

Amoebiasis is classified into intestinal and extraintestinal types, and the intestinal amoebiasis is further subdivided into dysenteric and non-dysenteric amoebic colitis. The extra-intestinal amoebiasis is the type that involves the liver, brain, spleen as well as other organs of the human body. Clinical presentation of the intestinal infection may include abdominal discomfort, weakness, malaise, constipation that may alternate with diarrhea, dysentery with the passage of exudates, blood and mucus as well as colicky abdominal pain. Systemic signs of infection include fever, rigors and polymorphonuclear leukocytes while liver abscess results from infection via the intra-hepatic portal vessels (Harold 1975, Haque 1995 Huston, Haque Williams, Peter, 1999). The diagnosis of ameobiasis is by finding and/or identifying the trophozoites and cysts in the stool and/or aspirates in the case of extra-intestinal amoebiasis. Amoebiasis had been described as a third world disease due to its high rate of prevalence in the poor countries of the tropics and subtropical zones of the world. The low socio-economic class shows a large prevalence probably due to malnutrition, inadequate disposal of faeces and the use of faeces as fertilizer in farming as all these lead to contamination of food and water. This is the portrait of the Degema Local Government Area of Rivers State where this study was conducted.

Unfortunately, there is paucity of information with regards to the prevalence of intestinal amoebiasis in the children of this area inspite of the increasing number of patients with this condition who attend the General Hospital in Degema (Stauffer, Abd-Alla and Ravdin, 2003; 0yerinde, Alonge, Adegbite-Hollist and Ogunbi, 2006). This represents the major import of this work. It is hoped that the result of this study will equip health care givers with the adequate information needed to address this health challenge in our environment.

* Corresponding author: Stanley H. O. 


\section{MATERIAL AND METHODS LOCATION}

The study was conducted among children (1-14 years) attending the General Hospital Degema in Rivers State of Nigeria. Patients from Degema and three other neighbouring villages, Usokun-Degema, Ililema and Okpor in Asari-Toru Local Government Area of Rivers State visit this General Hospital. These areas are rural communities inhabited by people whose predominant occupation is fishing. The study lasted from February to November, 2004.

\section{SAMPLE COLLECTION AND EXAMINATION}

Four hundred and five (405) faecal samples made up of $52.3 \%$ females and $47.7 \%$ males were collected from patients aged between 1 to 14 years who were in and out-patients of Degema General Hospital. Before the commencement of the study, informed consent was obtained from parents/guardians of the children or from the children directly were applicable. Clean dry faecal containers were given to them and/or their parents and instructed on how to collect the samples. Data concerning their sexes, ages and occupation were recorded on submission of samples.

All the faecal samples were examined macroscopically i.e. visually. The colour, odour, presence of mucus and/or blood were noted. The applicator sticks were used to test for consistency. Microscopic examination was subsequently done. The semi-formed and formed samples were processed by placing a drop of normal saline on one end of a clean glass slide and a small quantity of the sample added with the applicator stick; both were emulsified. Another emulsified mixture of normal saline and stool sample was carried out at the opposite end of the same glass slide. Individual preparations were covered gently with glass cover slips and examined with X10 objective of the microscope. The X40 objective was used to identify any observed object/organism of interest under good contrast of the microscope. Dobell's iodine was added in drops to stain observed cysts for easy identification. The applicator stick was used to carefully transfer watery stool samples onto the clean slides, covered with the cover slip and observed under the microscope, a drop of Eosine was added with the Pasteur pipette, to aid the identification of motile trophozoites. Formal ether concentration technique was used to concentrate cysts in the formed stool samples by the force of gravity. Four milliliter of formol water was placed in the screw capped testtube. The applicator stick was used to transfer about 1 gram of the faecal sample from the surface and several places and emulsified with the formol-water in the tube. The tube was capped and shaken vigorously to mix the content properly. The mixture was sieved with the gauze into the beaker as suspension. The suspension was transferred into a centrifuge tube and $3 \mathrm{ml}$ of ether was added; the tube was stoppered and content mixed properly for about 5 mins. A piece of tissue paper was used to wrap around the top of the tube and gradually uncapped. The preparation was then centrifuged at $3000 \mathrm{pm}$ for 2minutes.

A fresh applicator stick was used to loosen the thick layer of faecal debris at one side of the tube which was inverted to discard the formol water, ether and faecal debries, with the sediment remaining at the bottom of the tube. The tube was turned upright with the droplet of water solution on the side draining back into the tube. The tube was then tapped at the base to re-suspend the sedimented parasites. A fresh pastueur pipette was used to transfer the suspended mixture onto a clean glass slide. The preparation was viewed with the X10 objective of the microscope, with condenser iris sufficiently closed to give good contrast. The X40 objective was used to identify cysts and other parasitic contents of the preparations. A drop of iodine was run under the cover slips to aid the identification of cysts where present and accordingly recorded.

\section{RESULTS AND DISCUSSION}

Out of the 405 stool samples examined, 43(11\%) were positive, i.e., they contained cysts and/or trophozoites of E. histoytica. Seventeen of these samples belonged to male patients while 26 belonged to females. The distribution of the prevalence of infection among the various age groups showed that there was an increase from $12(9 \%)$ infections for the under fives to $18(12 \%)$ infections for patients aged between 6 and 10 years. The last group of 11-14 years shared in increase but not as much as the 6-10 year olds. (see table 1). Similarly, the 6-10 year age group had the greatest density of parasitaemia as evidenced by the highest number of parasites (35) see in their stools, relative to the two other age groups. The number of females infected were more than the males; 26(12.3\%) versus 17 (8.8\%) respectively. Besides, females' samples recorded higher parasite burden for all age groups compared to their male counterparts; $24,22,15$ versus $11,10,10$ respectively. However the difference between the rate of infection between the female and male subjects in this study is not statistically significant. $\left(\mathrm{X}^{2}=5.902, \mathrm{t}=1\right.$, $\mathrm{P}>0.05$ )

Furthermore, the 6-10 year olds, for both genders had the highest numbers of positive cases as well as parasite burden compared with the other age groups; $8(4.1 \%), 11$ and 10(4.7\%), 24 for males and females respectively. 
Table 1: Prevalence of Amoebiasis and Parasite Burden among various Age Groups

\begin{tabular}{llllll}
\hline $\begin{array}{l}\text { Age Grp } \\
\text { (yrs) }\end{array}$ & $\begin{array}{l}\text { No. of samples } \\
\text { examined }\end{array}$ & $\begin{array}{l}\text { No. of positive } \\
\text { cases \% }\end{array}$ & $\begin{array}{l}\text { No. of negative } \\
\text { cases \% }\end{array}$ & $\begin{array}{l}\text { No.(burden of parasites } \\
\text { cysts and trophozoites }\end{array}$ & \% (f parasites \\
\hline $1-5$ & 139 & $12(9 \%)$ & $127(91 \%)$ & 25 & 27 \\
$6-10$ & 148 & $18(12 \%)$ & $130(88 \%)$ & 35 & 38 \\
$11-14$ & 118 & $13(11 \%)$ & $105(89 \%)$ & 32 & 35 \\
\hline Total & 405 & $43(11 \%)$ & $362(89 \%)$ & 92 & 100 \\
\hline
\end{tabular}

Table 2: Sex Distribution of Infection and Parasite Burden among the Various Age Groups

\begin{tabular}{|c|c|c|c|c|c|c|c|}
\hline Age (Yrs) & \multicolumn{3}{|c|}{ Male N = 193} & \multicolumn{4}{|c|}{ Females N-212 } \\
\hline , & $\begin{array}{l}\text { No. of } \\
\text { samples }\end{array}$ & $\begin{array}{l}\text { No. of positive } \\
\text { cases }\end{array}$ & $\begin{array}{l}\text { No. of } \\
\text { parasites seen }\end{array}$ & $\begin{array}{l}\text { No. of } \\
\text { samples }\end{array}$ & $\begin{array}{l}\text { No. of positive } \\
\text { cases }\end{array}$ & $\begin{array}{l}\text { No. of } \\
\text { parasites seen }\end{array}$ & $\begin{array}{l}\text { Total no. of } \\
\text { parasites seen }\end{array}$ \\
\hline $1-5$ & 67 & $5(2.6 \%)$ & 10 & 72 & $7(3.3 \%)$ & 15 & 25 \\
\hline $6-10$ & 69 & $8(4.1 \%)$ & 11 & 79 & $10(4.7 \%)$ & 24 & 35 \\
\hline $11-14$ & 57 & $4(2.1 \%)$ & 10 & 61 & $9(4.2 \%)$ & 22 & 32 \\
\hline Total & 193 & $17(8.8 \%)$ & 31 & 212 & $26(12.3 \%)$ & 61 & 92 \\
\hline
\end{tabular}

\section{DISCUSSION}

Amoebic dysentery as caused by Entamoeba histolytica, also leads to extra-intestinal infections (Adam, Macloed, 1997). Even though there are luminal amoebiasis, as found in symptom less carriers, the invasive type is of medical concern. Various prevalence rates of E. histolytica infection had been published by different researchers. The rates vary for the different locations, states, and the types of patients surveyed and the source of the survey materials. While prevalence rate as low as $1 \%$ has been recorded (Pugh, Burrows, Bradely, 1981), rates as high as $35-41 \%$ have also been published (Reynoldson, Behnke, Pallant, Machnish Gilbert, Gilles, 1997). In Nigeria, rates of 1 and 13.7\% have also been established (Pugh, Burrows, Bradely, 1981; Alaribe, Utsalo, Gemade, Ejezie, 1994)). In his study of intestinal parasites in Sagbama, Ekeremor Local Government Area of Bayelsa State of Nigeria, Agi (1995) recorded a low prevalence of amoebiasis infection for children below 5 years for some and a high prevalence for children of farmers and fishing occupation. The latter group drinks water from streams and dug out wells that are usually or believed to be contaminated with human faeces (Agi, 1997). The prevalence rate of $\mathrm{E}$. histolytica among children in this study was found to be $11 \%$. Poor drainage system, unhygienic methods of disposing sewage as well as very low standard of personal hygiene in the rural communities from which the subjects were drawn may account for this high prevalence rate.

Among the three age categories represented in this study the children within age bracket of $1-5$ years were least infected, 12(9\%). This can be attributed to their innate resistance due to the induced production of secretory immunoglobulin A (Sig A) that can diminish the adhesion between E. histolytica trophozoites epithelial cells, hence reducing new infection (Barbosa-Sabanero and Avila, 2004). Also, the lack of antitrophozoite $\operatorname{IgG}$ and the acquired resistance due to intestinal $\operatorname{IgA}$ against the carbohydrate recognition domain of E. histolytica glactase N-Acetyl D-galactosamine lecitin is responsible for the partial immunity enjoyed by the under fives (Haque, Diggal, Ali, Hossaing, Mondal, and Sack, 2002). This study also revealed that the female children were more infected than the males proportionally, $26(12.3 \%)$ versus $17(8.8 \%)$ but the difference is not statistically significant. This is not surprising especially when one notes that both genders live in the same community and generally engage in similar activities such as fishing, farming, trading and are hence exposed to the same hazards continually. It must be stated emphatically, that nonspotting of cysts and/or trophozoites of E. histolytica from stool samples, aspirates from the spleen, liver or pleural abscess are not conclusive evidence of total absence of ameobiasis. Particularly from stool samples, there could be none to the presence of about 6 million cysts and trophozoites in patients suffering from E. histolytica infection. Positive results, presence of cysts and/or trophozoites in faecal samples in symptom-less carriers are the major source of infection as such carriers pass out through faeces about 100,000 cysts per day. The chances of spotting and/or identifying cysts by direct smear of formed stool samples are about $20 \%$ for one examination, and $50 \%$ for three examinations. Hence the requirement to establish a reliable diagnosis by several examinations increases the chances of obtaining positive results between $30 \%$ and $50 \%$ for one examination (Harold, 1975).

The non-availability of more advanced diagnostic techniques in local or rural hospitals and health centres like the Polymerase Chain Reaction (PCR) and Enzyme Linked Immunoabsorbent Assay (ELISA), serological tests for detecting the presence of anti-amoebic antibodies, and the delay in processing samples through culture methods with relevant facilities are major lingering problems. To 
control the spread of amoebiasis, legislations and policies aimed at creating the awareness for personal hygiene and sanitation should be enunciated. Reintroduction of functional sanitary inspectors and inspection units in all local government areas is essential. Organized housing units with water closets should be introduced for our rural populace. These measures were re-echoed by Harold "Sanitary methods of sewage disposal and the regulation of the use of human faeces as fertilizer should be measures that will help to control the spread of amoebiasis" (Harold, 1975). Treatment and close contact with identified asymptomatic carriers preventing them from the occupation of food handling and/or food vending, will go a along way to checking transmission of the infection. Boiling, pasteurization about $56^{\circ} \mathrm{c}$ and treatment with 3PPM of iodine or hypochlorite and sand filtrations in water facilities will go a long way in curtailing the spread off the infection in rural communities (Harold, 1975). Researches into vaccines for amoebisis are possible since there are studies that suggest innate and partial acquired immunity against intestinal amoebiasis (Barbosa-Sabanero and Avila, 2004; Haque, Diggal, Ali, Hossaing, Mondal and Sack, 2002). Researches into simpler methods of diagnosing the diseases, as well as the training and posting of health professionals to rural communities should be invigorated. The purpose is to raise the awareness of the rural populace about this illness as well as proper hygiene and for easy and early detection of cases.

In conclusion, this study is a contribution to the epidemiological survey of ameobiasis in Degema and the Niger Delta Region of Nigeria. A more elaborate study including adults is recommended. The findings will help to improve the health care delivery system in this part of Nigeria and in rural communities worldwide.

\section{REFERENCES}

Ravdin, J L; Petri, W A (1995). Entamoeba Histolytica (Amoebiases). Principles and Practice of Infectious Disease $4^{\text {th }}$ Edition. Churchill Livingstone. New York 2395-98.

Farthing, M S; Cavellos A M; Kelly P; Cook G C (1996). Intestinal Protozoa; In Manson's Tropical Disease. $20^{\text {th }}$ Edition, London W.B. Saunder Company. 1255-1267.

Allason-Jones, E M A; Sargeunt, P; Williams, P (1986). Entamoeba Histolytica, a Commensal Intestinal Parasite in Homosexual Men. North England Journal of Medicine 315:353-356.
Harold W B (1975). Entamoeba Histolytica in Basic Clinical Parasitology 4, 23-27, AppletonCentury-Croft/New York.

Haque R. (1995). Rapid Diagnosis of Entamoeba Histolytica Infection by using Entamoeba Histolytica Stool Antigen Detection Kits. Journal of Clinical Microbiology, (33): 2558-2565 7186.

Huston, C D; Haque R; Williams A; Peter J (1999) Molecular Based Diagnosis of Entamoeba Histolytica Infection. Experts Review in Molecular Medicine. 223-225.

Stauffer W; Abd-Alla M; Ravdin J (2003). Prevalence and Incidence of Entamoeba Histolytica Infections in South Africa and Egypt. Archives of Med. Research 37: (2), 265-268.

Oyerinde J P; Alonge A A; Adegbite-Hollist; Ogunbi O (2006). Age and Sex Distribution of Infection with Entamoeba Histolytica and Giardia Intestinalis in the Lagos Population. Internal Journal of Epidemiology 6: (3) 231-234.

Adam, E B; Macloed I N (1997). Invasive Amoebiasis II, Amoebic Liver Abscess and its Complicatins in Medicine. Baltimore (56, 325334).

Ackars, J P (2000). Amoebiasis. Department of Medical Protozology. London School of Hygiene and Tropical Medicine, Kepple Street, London, WCLE7HT, UK 145-147.

Pugh, R N Burrows, S W; Bradely A K (1981). Malumfashin Endemic Disease. Research project XVI, Findings of a Survey for Schistosoma Mansoni, Hookworm, Girdiasis, E. Histolytica and Nutritional Status. Annals of Tropical Medicine and Parasitology 75 (3): 279-281.

Reynoldson, J A; Behnke J M; Pallant L J; Machnish M G; Gilbert, F; Gilles, S (1997). Failure of Pyrantel in treatment of Human Hookworn Infections (Anclylostoma Duodenale) in the Kimberly Region North West Austrialia. Acta Tropica. 63 (30 301-312.

Alaribe, A A; Utsalo, S J; Gemade E L; Ejezie G C (1994). Brine Flotation (BF)as a Standard Technique for the Detection of Poly Parasitism from Stool. Journal of Medical Laboratory Science $4 ; 16-20$.

Agi, P I (1997). Comparative Helminth Infections of Man in two Rural Communities of the Niger Delta, Nigeria. The West African Journal of Medicine 16(4); 232-6. 
Barbosa-Sabanero, G; Avila E (2004). Recognition of Entamoeba Histolytica IIS, KDA Surface Protein by Human secretory immunoglobulin from asymptomatic carriers. Journal of Parasitology Institute De Investidcion En Biologia Experimental Facultad De Quimica Unersida De Guanajuato, Mexico PMID: 15165062.
Haque, R; Diggal, P; Ali, I M; Hossaing M B; Mondal D; Sack R B (2002). Innate and Acquired Resistance to Amoebiasis in Banglandesh Children, Journal of Intestinal Disease (186) 547-52, Pubmed: 112195383. 